\title{
Demand for Water-based Leisure Activity
}

\section{JOHN A. CURTIS}

Economic and Social Research Institute, 4 Burlington Road, Dublin 4, Ireland. E-mail: john.curtis@esri.ie

(Received March 2002; revised August 2002)

ABSTRACT This paper reports on the demand for water-based leisure activity in Ireland based on data from a nationally representative telephone survey. Participation and trip demand are modelled using an augmented Poisson count model and consumer surplus welfare estimates are derived. The model is also used to investigate the level of social exclusion in water-based leisure activity. The demand for four activities is examined: sea angling, boating, swimming and other beach/sea/island day-trips. Results indicate that Irish rivers, wetlands, estuaries and seas are highly valued, while there is some evidence of social exclusion in water-based leisure activity.

\section{Introduction}

Marine and inland water resources provide a multitude of recreational opportunities including fishing, boating, scenic walkways and wildlife observatories. Over $56 \%$ of Irish adults engage in some leisure activity connected with sea or fresh water each year, with combined expenditures estimated at $0.9 \%$ of gross national product per annum (Marine Institute, 1997). Less obvious than the economic benefits of leisure activity is the importance of recreation in social infrastructures. Social interaction is among the most frequently reported reasons for participation in leisure activities (Auld \& Case, 1997) and participation in leisure activity leads to community building (Arai \& Pedlar, 1997). Leisure opportunities are also an important determinant of people's perception of quality of life (Jefferes \& Dobos, 1993), while family participation in leisure activities has positive effects on family interaction, satisfaction and stability (Orthner \& Mancini, 1990). Despite the social and economic importance of leisure activity there is a dearth of published estimates on the value of and the demand for water-based recreational activity with recreational fishing being the one significant exception.

Under the Irish government's National Development Plan there is an ambitious marine leisure investment programme. The plan covers the period 2000-06 and investment totalling $\mathbf{E} 165$ million is proposed, of which $\mathbf{E 1 2 2}$ million is public funds. ${ }^{1}$ The purpose of the proposed investment is to enhance the contribution the water-based tourism and leisure sectors make to Ireland's economic and social welfare. Key principles of the investment strategy are: quality improvements of the water-based leisure resource; the building of critical 
mass within the water-based tourism and leisure sector; and promoting environmentally sustainable development (Marine Institute, 2000).

The Marine Institute (2000) forecasts that the $\mathbf{E 1 6 5}$ million investment across the water-based tourism and leisure sectors will result in an annual net additional economic impact of $\mathbf{\epsilon} 234$ million by 2006, with over 8000 additional jobs. The potential social benefits of the investment have not been forecast. Neither has there been any attempt to estimate the magnitude of the potential benefits from individual water-based leisure activities. One objective of the paper is to investigate the demand for four individual water-based leisure activities, report valuation estimates and discuss these in light of the proposed investment.

Two conditions of National Development Plan (1999) investments are equal opportunity and the promotion of social inclusion. There is some, albeit mixed, international evidence that social exclusion persists in leisure activity. For example, Kay \& Jackson (1991) report that constraints to leisure activity in the UK do not always prevent participation and, while Shaw et al. (1991) report similar findings for Canada, they also find that social structural constraints (namely age, gender, lifestyle, occupational status and income) affect participation levels. Dardis et al. (1994) find that income and education have significant impacts on the level of leisure expenditures in the USA, and therefore participation, while Kuentzel \& Heberlein (1997) report that income and social status affect the entry level and style of involvement but not participation in leisure activity. This paper investigates the occurrence of exclusion in water-based leisure activity in Ireland. In the sectors where social exclusion appears prevalent, which include boating activities, the paper advocates additional scrutiny of public fund investment to ensure projects are adequately proofed for equality and inclusion.

Promotion of individual water sports and leisure activities resides with local clubs and organizations and in some cases with national governing bodies. Even so, participation in water-based leisure activity is not predicated on club involvement and access to the water resource is open and free, with the state holding ownership of the foreshore. ${ }^{2}$ The tourism and leisure section of Ireland's Marine Institute implements a range of initiatives and actions aimed at catalysing development of the marine resource in Ireland. Included in its work is the formation of appropriate policies and guidelines for sustainable development of the water-based leisure resource, including equality of access and participation. While exclusion may not be a widely prevalent problem, the results indicate that work is still required to improve access and participation.

The paper proceeds by discussing the data used to examine water-based leisure demand. The model used to analyse the data is then explained, model estimates are presented and the paper concludes with a discussion of the results and policy implications.

\section{Survey and Data}

During the summer of 1996 a survey module on water-based leisure was included in a monthly nationally representative telephone survey of Irish residents. A nationally representative sample was achieved by telephone and in-person surveys drawn from the electoral register, as well as a quota of responses from randomly generated telephone numbers within each electoral division. The purpose of the leisure survey was to quantify the level of 
water-based leisure activity in the previous 12 months in Ireland. In total there were 3920 responses to the survey but due to missing values for the variables used in estimation and exclusion of high-frequency users the sample sizes used in the analysis are lower. ${ }^{3}$ The analysis here focuses on demand for day-trips in the following activities: sea angling; boating (including sailing and cruising); swimming in the sea; and other beach/island/sea trips. Table 1 summarizes the socio-economic data. The day-trip cost data (TRIPCOST) relate to all costs incurred per trip, such as travel, meals and equipment hire, but specifically exclude purchase of equipment. Participants in each activity are roughly similarly distributed in their educational attainment, age and income levels, except perhaps for boating and sea angling. Sea anglers are disproportionately older males, while boating participants are disproportionately younger and more highly educated. Variables HHD1 and HHD2 in Table 1 are the number of children ( $<18$ years) and adults ( $\geq 18$ years) in the participant's household and the figures suggest that water-based leisure activity participants come from households with a high number of occupants, children or adults, compared to the sample as a whole. Much more detail on the results of the survey is available in Marine Institute (1997).

Unfortunately, the data set did not contain variables measuring the proximity of the respondent's residence to marine/inland water, club memberships, equipment ownership and family participation. These items are also likely to affect participation and demand for water-based activities.

The data set is used to model trip demand for angling, boating, swimming and other water-based leisure trips. The proportion taking one or more trips varies between $3 \%$ and $35 \%$, meaning that the majority of people do not make leisure trips in each of the leisure activities. There are at least two potential reasons why individuals undertake zero trips. First, for health or preference reasons, some individuals will not undertake leisure trips irrespective of cost, as the particular activity does not enter the utility function. Secondly, where the leisure activity does enter the utility function, the individual may select to make zero trips, i.e. a utility-maximizing corner solution. This category includes people who were excluded from involvement for economic or social reasons. Excluded individuals can be considered zero trip participants since the activity may provide utility but no trips are taken.

In modelling trip demand we need to be cognizant of the 'excess' zeros, i.e. between $65 \%$ and $97 \%$ of individuals take zero trips, and that not all individuals surveyed are potential participants in the leisure activity. Count models are frequently used to model trip demand, where recreational trips are modelled as non-negative integer valued variables (Shaw \& Jakus, 1996; Shonkwiler \& Shaw, 1996; Chakraborty \& Keith, 2000), though sample selection models such as the Tobit, Heckman and Cragg models are also used (Bockstael et al., 1990). The most common count models rely on the Poisson or negative binomial discrete distributions but both models require adjustment to handle excess zeros in the sample. If we are just interested in recreational demand conditional on participation the temptation is to truncate the sample at positive trips demanded and estimate models such as those used by Grogger \& Carson (1991) and Englin \& Shonkwiler (1995). However, sample truncation potentially discards information. Grogger \& Carson (1991) derive consistent parameter estimates when they account for the truncation in the estimation process in the absence of zeros. Haab \& McConnell (1996) argue that their augmented count models must 
Table 1. Descriptive statistics

\begin{tabular}{|c|c|c|c|c|c|}
\hline & Sample $^{a}$ & $\begin{array}{c}\text { Sea } \\
\text { angling }\end{array}$ & Boating & Swimming & $\begin{array}{c}\text { Other } \\
\text { beach/sea } \\
\text { trips }\end{array}$ \\
\hline Total sample $^{\mathrm{a}}$ & 3920 & 3202 & 3175 & 2980 & 2742 \\
\hline Activity participants & NA & 92 & 146 & 476 & 958 \\
\hline Mean trips of total sample & NA & 0.23 & 0.30 & 1.27 & 1.74 \\
\hline $\begin{array}{l}\text { Mean TRIPCOST }(£) \text { (active } \\
\text { participants only) }\end{array}$ & NA & 5.92 & 15.44 & 8.76 & 1.60 \\
\hline Maximum TRIPCOST $(£)$ & NA & 55.00 & 240.00 & 250.00 & 50.00 \\
\hline $\begin{array}{l}\text { MALE (\%) } \\
\text { Age }(\%)\end{array}$ & 0.49 & 0.87 & 0.60 & 0.54 & 0.44 \\
\hline $16-29$ & 0.19 & 0.13 & 0.18 & 0.22 & 0.21 \\
\hline 30-49 (AGE2) & 0.44 & 0.48 & 0.50 & 0.45 & 0.42 \\
\hline 50-64 (AGE3) & 0.21 & 0.18 & 0.20 & 0.19 & 0.21 \\
\hline$>65$ (AGE4) & 0.16 & 0.21 & 0.12 & 0.14 & 0.16 \\
\hline \multicolumn{6}{|l|}{ Educational level (\%) } \\
\hline Primary & 0.20 & 0.24 & 0.11 & 0.19 & 0.22 \\
\hline Attended secondary (EDUC2) & 0.25 & 0.25 & 0.27 & 0.26 & 0.24 \\
\hline Completed secondary (EDUC3) & 0.24 & 0.26 & 0.23 & 0.21 & 0.23 \\
\hline Post-secondary qualification (EDUC4) & 0.10 & 0.09 & 0.12 & 0.11 & 0.09 \\
\hline Tertiary level (EDUC5) & 0.21 & 0.16 & 0.27 & 0.23 & 0.22 \\
\hline \multicolumn{6}{|l|}{ Income ( $£ 1000$ per annum) (\%) } \\
\hline$<£ 6.75$ & 0.18 & 0.15 & 0.14 & 0.16 & 0.18 \\
\hline$£ 6.75-11.5$ (INCM2) & 0.31 & 0.33 & 0.31 & 0.29 & 0.32 \\
\hline £11.5-19 (INCM3) & 0.30 & 0.25 & 0.28 & 0.29 & 0.29 \\
\hline$>£ 19$ (INCM4) & 0.21 & 0.27 & 0.27 & 0.26 & 0.21 \\
\hline $\begin{array}{l}\text { Number in household }<18 \text { years } \\
\text { (HHD1) }\end{array}$ & 100 & 125 & 121 & 148 & 123 \\
\hline Number in household $\geqslant 18$ years (HHD2) & 2.43 & 2.63 & 2.79 & 2.54 & 2.51 \\
\hline
\end{tabular}

NA, Not applicable.

${ }^{a}$ Total survey sample contained 3920 observations. Activity samples are less than 3920 because observations not containing all relevant socio-demographic and cost data were excluded, as were high-frequency resource users. High-frequency users were excluded because their circumstances and demand for the activity will structurally differ from the wider sample. For example, a person who lives beside a beach is likely to swim, boat, fish or walk on the beach much more frequently than others simply because of the easy access and the travel cost model is not appropriate to estimate demand.

perform equally well in terms of efficiency parameter estimation because their models explicitly recognize the contribution of the zeros to the likelihood function and thereby extract information from the zero observations. Essentially, Haab \& McConnell (1996) suggest that participation should not be predicated on positive trip demand and their model allows for participants who make zero trips, for whatever reason.

A frequent criticism of the Poisson model is that the Poisson's mean and variance of the dependent variable must be equal, which if overdispersion exists results in underestimates of the standard errors. This paper estimates Haab \& McConnell's (1996) augmented Poisson model, which relaxes the restriction on the moments and provides a solution with an economic interpretation to the overdispersion problem. 


\section{Augmented Poisson Model ${ }^{4}$}

Let $y_{i}$, the number of leisure trips demanded by individual $i$, have a non-negative discrete probability density function (PDF) defined as $P\left(Y=y_{i}\right)=f_{o}\left(y_{i}\right)$ with $y_{i}=0,1,2,3, \ldots$. The basic Poisson model can be written as $f_{p}\left(y_{i}\right)=e^{-\lambda_{i}} \lambda_{i}^{y_{i}} / y_{i}$ ! where the Poisson parameter $\lambda_{i}$ is defined as a function of exogenous explanatory variables. In the augmented count model an individual specific weight parameter $\left(w_{i}\right)$ is introduced into the PDF such that the probability of observing a zero value for the dependent variable is increased by $w_{i}$, and the probability of observing other values of the dependent variable decreased by $\left(1-w_{i}\right)$. The efficiency gain from the inclusion of the zero observations depends on the probability of observing a zero observation conditional on participation in the leisure activity, with efficiency increasing as the mean of the dependent variable conditional on participation decreases (Haab \& McConnell, 1996). In the context of leisure demand, $w_{i}$ represents an index of factors that affect the participation decision. The augmented PDF of $y_{i}$ is: ${ }^{5}$

$$
f_{\mathrm{A}}\left(y_{i}\right)= \begin{cases}w_{i}+\left(1-w_{i}\right) f_{0}(0) & y_{i}=0 \\ \left(1-w_{i}\right) f_{0}\left(y_{i}\right) & y_{i}=1,2,3 \ldots\end{cases}
$$

The probability of a zero trip observation is given by the sum of the probability that the individual is a non-participant, i.e. $w_{i}$, and the probability that the individual is a participant making zero trips, i.e. $\left(1-w_{i}\right) f_{0}(0)$. Socially excluded individuals are part of the latter category. The augmented Poisson PDF can then be written as:

$$
f_{\mathrm{AP}}\left(y_{i}\right)= \begin{cases}w_{i}+\left(1-w_{i}\right) e^{-\lambda_{i}} & y_{i}=0 \\ \left(1-w_{i}\right) \frac{e^{-\lambda_{i}} \lambda_{i}^{y_{i}}}{y_{i} !} & y_{i}=1,2,3 \ldots\end{cases}
$$

with $E\left(y_{i}\right)=\left(1-w_{i}\right) \lambda_{i} \quad$ and $\operatorname{Var}\left(y_{i}\right)=\left(1-w_{i}\right)\left(1-w_{i} \lambda_{i}\right) \lambda_{i} \quad$ compared to $E\left(y_{i}\right)=\operatorname{Var}\left(y_{i}\right)=\lambda_{i}$ in the basic Poisson model.

In the context of recreational demand, the demand for trips can be defined such that $y_{i}=e^{X_{i} \beta+\varepsilon_{i}}$, where trips demanded by individual $i\left(y_{i}\right)$ are a function of a $K \times 1$ vector of parameters $\beta$ and $X_{i}$, a $1 \times K$ vector of explanatory variables for individual $i$. For the purposes of regression estimation $\lambda_{i}$ is defined as $\lambda_{i}=e^{X_{i} \beta}$. The term $e^{\varepsilon_{i}}$, where $\varepsilon_{i}$ is the residual stochastic error, is further defined such that its density function implies a count distribution for $y_{i}$. Following Haab \& McConnell (1996) in this regard, the consumer surplus (CS) measure for the augmented Poisson is calculated as

$$
E\left[\operatorname{CS}\left(e^{X_{i} \beta+\varepsilon_{i}}\right)\right]=\frac{\lambda_{i}}{\beta_{p}} E\left(e^{\varepsilon_{i}}\right)=\frac{\lambda_{i}}{\beta_{p}}\left(1-w_{i}\right)
$$

where $\beta_{p}$ is the parameter on the trip price explanatory variable. For estimation $w_{i}$ is assumed to be a function of individual specific variables that affect the leisure participation decision, which might include age, education level or even economic variables. ${ }^{6}$ For estimation the following functional form was used: $w_{i}=1-e^{Z_{i \gamma}}$, where the matrix $Z_{i}$ represents the variables explaining the participation decision and $\gamma$ is the associated parameter vector. When $\gamma=0, w_{i}=0$ and the augmented Poisson becomes the standard Poisson count model. 


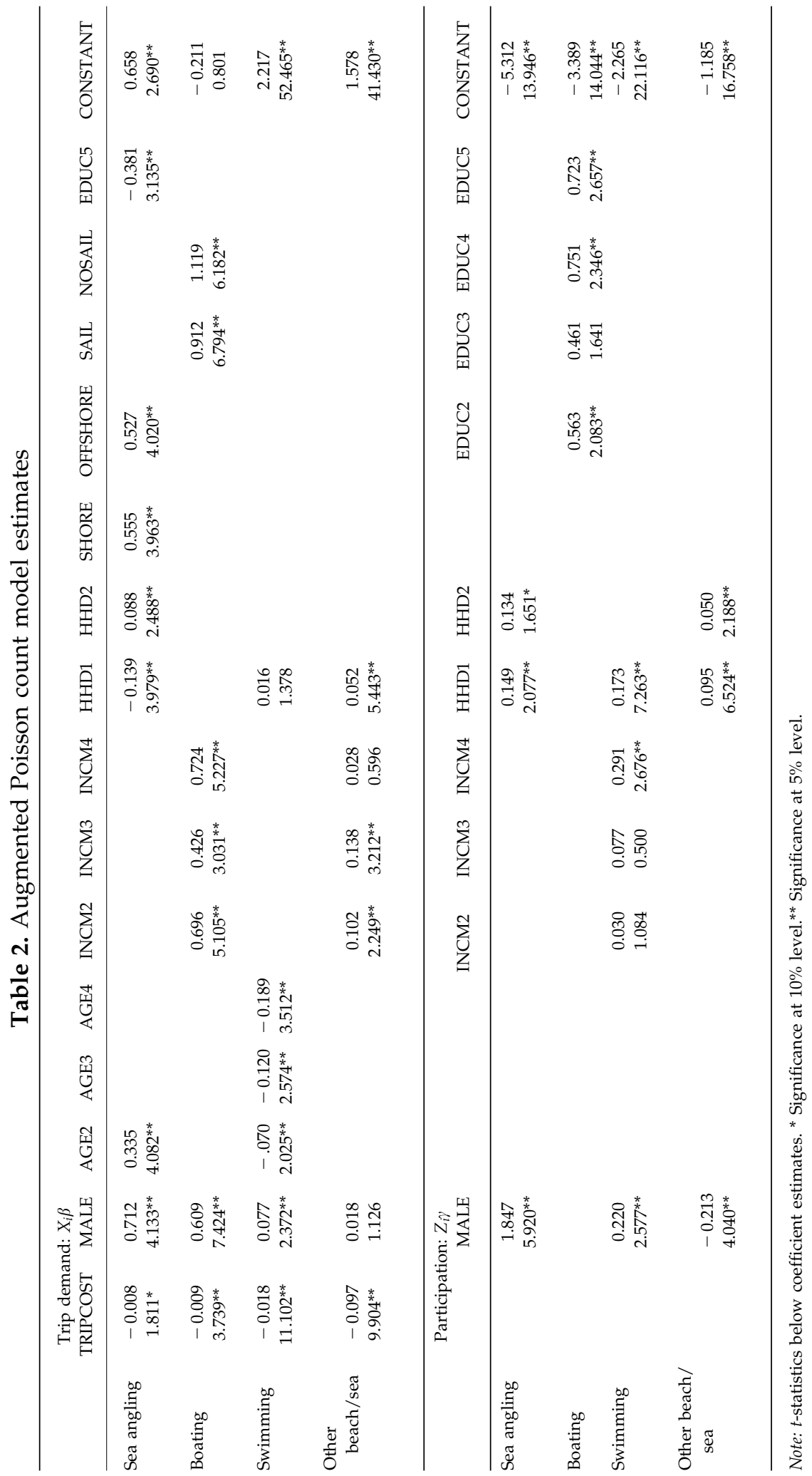




\section{Augmented Poisson Model Estimates}

The model was estimated by maximum likelihood and the results for the four activities are contained in Table 2. Similar models with other explanatory variables included in both $\lambda_{i}$ and $w_{i}$ were estimated but provided no additional insights to the models presented.

\section{Model Fit}

Table 3 presents the value of the likelihood function for the four models, as well as the likelihood for the restricted model, which is the basic Poisson count model. In each instance the augmented Poisson model gives a better fit to the data. The likelihood ratio test statistics are included in the table. The model also allows calculation of the samples' total trip demand, which can be compared with actual trip demand. For example, estimated mean swimming trip demand is 1.322 trips, which, multiplied by a total sample size of 2980, gives an estimated sample total trip demand of 3940 trips. Actual total swimming trip demand by the sample was 3779 trips so the augmented Poisson works well in replicating total trip demand in this sample, as it does in the other beach/sea trip category, where estimated total trip demand is 5004 compared to total actual trips of 4775 . The augmented Poisson is less satisfactory explaining sea fishing and boating trip demand, where estimated total trip demand is $27 \%$ and $34 \%$ of actual total sample trip demand.

To further assess the augmented Poisson model's performance at estimating trip demand a demand function conditional on positive trip demand was estimated using a truncated negative binomial count model (TNB). ${ }^{7}$ TNB estimates of total sample trips are also presented in Table 3. In the four leisure categories, estimated total trip demand is comparatively close to actual total trip demand, with the largest difference less than 13\%. This result verifies the poor performance of the augmented Poisson at estimating trip demand in the angling and boating samples. The augmented Poisson's poor performance for these two samples may be because participation and demand are more complex than the

Table 3. Additional model estimates

\begin{tabular}{|c|c|c|c|c|}
\hline & $\begin{array}{c}\text { Sea } \\
\text { fishing }\end{array}$ & Boating & Swimming & $\begin{array}{c}\text { Other } \\
\text { beach/sea } \\
\text { trips }\end{array}$ \\
\hline Log likelihood & -777.8 & -1263.0 & -3215.3 & -4308.2 \\
\hline Restricted log likelihood & -1015.8 & -1386.4 & -8492.6 & -7378.5 \\
\hline Likelihood ratio test $\left(\chi^{2}\right)$ & 476.152 & 246.77 & 10554.5 & 6140.67 \\
\hline Total sample & 3202 & 3175 & 2980 & 2742 \\
\hline Number of participants & 92 & 146 & 476 & 958 \\
\hline Estimated mean trip demand & 0.062 & 0.102 & 1.322 & 1.825 \\
\hline Estimated sample total trips & 199 & 324 & 3940 & 5004 \\
\hline Actual sample total trips & 726 & 962 & 3779 & 4775 \\
\hline TNB estimated sample total trips & 667 & 841 & 3644 & 4648 \\
\hline Augmented Poisson mean consumer surplus $(£)$ & 8.09 & 11.95 & 71.69 & 18.90 \\
\hline TNB mean consumer surplus $^{a}(£)$ & 14.01 & 8.91 & 57.28 & 14.47 \\
\hline
\end{tabular}

TNB, Truncated negative binomial count model.

${ }^{a}$ TNB model mean consumer surplus adjusted by proportion of sample who are non-participants. 
survey data are able to reveal. For instance, demand for fishing and boating may be dependent on easy water access or family participation to a greater extent than the other leisure activities and the data set did not contain such variables. Additionally, in these two samples the participation level was the lowest of the four samples $(2.9 \%$ and $4.6 \%$ compared to $16 \%$ and $34.9 \%)$, meaning that there were relatively few observations with which to reveal the true nature of participation and demand.

\section{Participation/Non-participation}

Remembering that negative valued coefficients indicate an increased probability of not participating, we begin looking at the estimates for the sea angling model in Table 2. The probability of participation in angling is higher for males and for individuals with larger families, comprised of either children or adults. The only significant variable found to explain participation in boating activity is education. Those with higher levels of education have a higher probability of participating. The probability of engaging in swimming in the sea increases with the number of children in the household and also with higher levels of income. The fourth leisure activity includes other beach or seaside trips, including trips to islands, but excluding boating, swimming and nature watching day-trips. The model estimates suggest that male individuals with larger families, comprised of either children or adults, have a higher probability of engaging in these types of beach/sea/island trips but no other variables were found to have significant explanatory power.

\section{Exclusion}

The term $\left(1-w_{i}\right) \mathrm{e}^{-\lambda_{i}}$ from the augmented Poisson gives the probability that an individual is a zero trip participant, i.e. is excluded. Therefore, the probability of exclusion is a function of both the factors that affect the level of demand and the factors that affect participation.

The probability that an individual is excluded from active participation in sea angling, swimming and other beach/sea trip activities does not substantially differ depending on any of the socio-demographic variables examined. For boating activity several factors affected the probability of exclusion. The probability of exclusion is higher if female at $1.7 \%$ or highly educated at $1.9 \%$ or both female and highly educated at $3.4 \%$ compared to a male with the lowest educational attainment at $0.9 \% .{ }^{8}$ But income is the dominant factor that affects the probability of exclusion, with the probability of a male in the lowest income category being excluded falling from $1.9 \%$ (3.4\% if female) to $0.5 \%(1.6 \%$ if female) when the individual is in the highest income bracket. ${ }^{9}$ However, factors other than deliberate social discrimination, such as the relatively high cost of boating equipment, may also deter participation, although the data set contained no information of this nature.

The cost of a day-trip has a large effect on the probability that an individual is excluded, especially for boating and other beach/sea/island trip activities. As the cost of a boating day-trip increases up to $£ 240$, the maximum day-trip cost in the sample, the probability of exclusion increases from as low as $0.2 \%$ to as high as $6.3 \%$ depending on gender, income and education. In the case of other beach/sea/island trips the effect of trip price on exclusion is even more 
dramatic. At $£ 0$ cost the probability of exclusion is approximately $0.2 \%$ for a female, at $£ 25$ the probability is $25 \%$, and at $£ 50$, which is the maximum day-trip cost in the sample, the probability of exclusion is $39 \% .{ }^{10}$ For sea angling and swimming the cost of day-trips does not substantially affect the probability that an individual is excluded from active participation.

\section{Demand}

Although there is a higher probability of sea angling participation among large families, the demand equation suggests that, given participation, demand increases with more adults but fewer children in the household. An expectation prior to estimation was that there would be higher trip demand by those engaged in on-shore angling, as less preparation time is required and shore fishing is less dependent on good weather conditions. The SHORE and OFFSHORE variables are dummies for respondents fishing from the shore and/or from a boat and the estimated coefficient on the SHORE variable was therefore expected to be higher than the OFFSHORE coefficient, which it is, but statistically the coefficients do not differ.

Given participation in boating activities, income has a significant and positive effect on trip demand. The SAIL and NOSAIL variables were included to distinguish between demand for sailing trips, boating/canoeing/motor-boat trips and inland water cruising trips. The lower-valued coefficient on SAIL compared to NOSAIL indicates that sailors demand fewer day trips than boating/canoeing/motor-boat enthusiasts. As both coefficients are positive, daytrip demand for inland cruising is lowest, which is as expected, since it is more common as a multiple day activity. As with all four activities, demand by males is higher than that by females.

While the number of children in a household affects participation in swimming, it does not appear to affect the level of demand, given participation. The coefficient estimates on the age variables in the swimming demand equation indicate declining demand with age. Unlike swimming demand, demand for other beach or seaside trips increases with higher numbers of children in the family.

The effect of trip cost on trip demand can be examined through the calculation of the price elasticity of demand, which is given by the term $\beta_{p} \mathrm{X}_{p}$, where $\beta_{p}$ is the parameter on the trip cost variable $X_{p} \cdot{ }^{11}$ The elasticity varies with price and calculated elasticities are presented in Table 4 over the range of typical day-trip travel costs in the samples. A surprising finding is that demand for all four activities is very price inelastic at the mean level of day-trip costs. ${ }^{12}$ For example, at $£ 5$ cost for a sea angling day-trip (compared to mean trip cost of $£ 5.92$ in Table $1)$, the price elasticity is -0.04 . A priori we would have expected the reverse, that leisure activities are price elastic. However, at higher trip costs demand for boating, swimming and other beach/sea trips becomes elastic. The high price elasticity of demand for other beach/sea trips at relatively low cost (i.e. - 2.43 at $£ 25$ ) means that demand for such trips would decline dramatically if there were even moderate increases in the cost of visiting marine amenity areas. From a policy perspective, if the government intends to recover some of the cost of its proposed investment in the water-based leisure sector by introducing access fees (e.g. for use of new slipways), it is likely that the revenue from such pay-per-use facilities will be substantially lower than expected. On the other hand, the price 
Table 4. Price elasticity estimates

\begin{tabular}{lcccc}
\hline $\begin{array}{l}\text { Day-trip } \\
\text { travel cost }(£)\end{array}$ & $\begin{array}{c}\text { Sea } \\
\text { fishing }\end{array}$ & Boating & Swimming & $\begin{array}{c}\text { Other beach/ } \\
\text { sea trips }\end{array}$ \\
\hline 1 & -0.01 & -0.01 & -0.02 & -0.10 \\
5 & -0.04 & -0.05 & -0.09 & -0.49 \\
10 & -0.08 & -0.09 & -0.18 & -0.97 \\
25 & -0.20 & -0.23 & -0.45 & -2.43 \\
50 & -0.40 & -0.45 & -0.90 & -4.85 \\
75 & & -0.68 & -1.35 & \\
125 & & -1.13 & & \\
175 & & -1.58 & & \\
225 & & -2.03 & & \\
\hline
\end{tabular}

elasticity of demand for sea angling trips is very low over the complete range of trip costs in the sample; however, it would be both politically infeasible and practically impossible to implement an access fee for angling in marine waters.

\section{Welfare}

Mean CS was calculated for the augmented Poisson model and for the TNB for comparison. To allow comparison with the TNB's CS estimate, which is conditional on positive trip demand, the TNB's CS estimate is adjusted to allow for the proportion of the sample with zero trips whose mean CS is assumed to be zero. ${ }^{13}$ Estimated mean CS per person is high irrespective of model, varying between $£ 8.09$ for sea fishing ( $£ 13.62$ in the TNB model) to $£ 71.69$ for swimming ( $£ 49.39$ in the TNB model), as shown in Table 3.

To derive aggregate national figures the adult population is used as a grossing factor. Estimated national expenditure equalled $£ 3.5$ million for sea angling in $1996, £ 11.9$ million for boating, £28.5 million for swimming and $£ 7.1$ million for other beach/sea trips. ${ }^{14}$ The estimated national consumer surplus based on the augmented Poisson estimates is $£ 20.7$ million for sea angling day-trips, $£ 30.6$ million for boating, £183.5 million for swimming and $£ 48.4$ million for other beach/sea trips. ${ }^{15}$ It is clear from these estimates that the public's valuation of water-based resources is very high. The total value of water-based marine leisure activity is likely to be substantially higher, as the estimates above relate to day-trip activity for four leisure activities only, excluding overnight trips and activities such as inland water angling and nature observation.

The Marine Institute (2000) is confident that the proposed investment of E165 million over 2000-06 will see a positive economic return of $\mathbf{E} 234$ million by 2006. Based on the expenditure and surplus estimates for just the four leisure activities examined, such optimism is not unrealistic, though whether its forecast is exactly realized remains to be seen. But even if the investment falls short on making a positive economic return, consideration of the social benefits may make the investment worthwhile. The social benefits, such as those highlighted by Auld \& Case (1997), Jefferes \& Dobos (1993) and Orthner \& Mancini (1990), are difficult to measure in monetary terms but are nonetheless part of the return to public fund investment. Based on the estimated large surplus enjoyed by the public, or at least water-based leisure users, it seems likely that invest- 
ment of public funds to enhance and protect water-based leisure amenities would receive favourable support.

\section{Conclusions}

Across the four activities examined, factors influencing participation varied and there was no singular aspect that explained why people participate in waterbased leisure activity. Family size, education and income all play a role to some extent. Factors such as proximity to a water resource or association with people who already participate presumably also affect participation levels but this type of information was not available from the survey data.

The cost of participation in water based leisure activities is a significant factor that affected both the participation decision and the level of demand, though the extent varied by activity. Boating activity, including sailing and cruising, appears to be the only activity where social exclusion appears to prevail. The model estimates indicate that more highly educated and/or female individuals are excluded from active participation. Individuals on lower income levels were also more likely to be excluded. Closer examination of boating activity is required to confirm this result but boating-based leisure projects should be vetted to ensure equality of access before public funds are committed.

An important policy implication of the price elasticity estimates is that while demand may be price inelastic at average trip costs, demand becomes very elastic as costs increase. The other beach/sea/island trips category has the highest participation rate at $35 \%$ and also the lowest average day-trip costs at just $£ 1.60$ per trip. However, demand for such trips is very elastic at moderate costs and, should the cost of engagement increase considerably, demand would fall substantially.

People are increasingly aware of the importance of protecting our water-based natural resources, not least because they enjoy or have the opportunity to enjoy these resources through their leisure activity. Unfortunately, these resources are not always afforded the protection they merit because in many situations their value is not known. It is therefore important that our non-market amenity resources are periodically valued so that resource use decisions are fully informed. This paper provides estimates of the value of Irish water-based leisure activity, with all four activities examined being highly valued. The valuation estimates presented also signal the public's value for the work of agencies involved in the prevention, monitoring and clean-up of water pollution. But day-trip leisure activity of water resources constitutes only a minority of possible uses and values. The total value of water-based resources, including use and non-use value, is likely to be several multiples of the total aggregate estimates presented here.

\section{Acknowledgements}

The author would like to thank Anne Wilkinson, Marine Institute, Dublin, for providing access to the survey data on which the analysis is based, and anonymous referees whose suggestions helped improve the paper. 


\section{Notes}

1. In $1996 \operatorname{IRL} £ 1=\mathrm{US} \$ 1.60=\mathrm{Stg} £ 1.03$, approximately. $\mathrm{IRL} £ 1=\mathbf{\epsilon} 1.27$.

2. However, some freshwater angling requires a licence and some locations may charge berthing fees for boats. Generally, access to water and participation in the activities does not involve a fee but equipment, which can be hired, may be necessary for some activities.

3. High-frequency users were excluded because their demand is structurally different from that of the majority of the sample and the travel cost approach is inappropriate for resource users who live adjacent to the resource.

4. This follows Haab \& McConnell (1996).

5. Johnson et al. (1972) call this the zero added class of distributions. Lambert (1992) and Shonkwiler \& Shaw (1996) present empirical applications of similar models.

6. A trip cost variable was not included in $w_{i}$ for estimation because such a variable was not available for individuals undertaking zero trips.

7. See Chakraborty \& Keith (2000) for an example of a TNB. A truncated Poisson model was not estimated, as it is not suitable in the presence of overdispersion (Grogger \& Carson, 1991). Haab \& McConnell's (1996) augmented negative binomial count model was a potential alternative but it has a complex distribution and in the author's attempts to estimate it he was unable to find convergence of the likelihood to a maximum.

8. These probabilities are for individuals in the lowest income category

9. These probabilities are for a male (female) with a tertiary-level education.

10. For a male the probabilities are $0.1 \%$ at $£ 0,20 \%$ at $£ 25$ and $32 \%$ at $£ 50$. Neither the individual's income level nor the number of household occupants substantially affects these probabilities.

11. $E(Y \mid X)=\left(1-w_{i}\right) \lambda_{i} . \quad \frac{\partial E(Y \mid X)}{\partial X_{j}}=\left(1-w_{i}\right) \lambda_{i} \beta_{j}, \frac{\partial w_{i}}{\partial X_{j}}=0 \therefore \frac{\partial E(Y \mid X)}{\partial X_{j}} \frac{X_{j}}{E(Y \mid X)}=\beta_{j} X_{j}$

12. Similar elasticity estimates were obtained for demand models estimated conditional on participation but are not reported here.

13. The adjusted $\mathrm{CS}=\mathrm{CS}_{\mathrm{TNB}} \times$ (proportion of total sample with positive trip demand).

14. Calculated as active participants' mean trip cost (Table 1$) \times$ mean trips (Table 1$) \times 2.56$ million adults.

15. Calculated as augmented Poisson mean CS (Table 3) $\times 2.56$ million adults.

\section{References}

Arai, S.M. \& Pedlar, A.M. (1997) Building communities through leisure: citizen participation in a healthy communities initiative, Journal of Leisure Research, 29, pp. 167-182.

Auld, C.J. \& Case, A.J. (1997) Social exchange processes in leisure and non-leisure settings: a review and exploratory investigation, Journal of Leisure Research, 29, pp. 183-200.

Bockstael, N.E., Strand, I.E. \& McConnell, K.E. (1990) Sample selection bias in the estimation of recreation demand functions: an application to sportfishing, Land Economics, 66, pp. 40-49.

Chakraborty, K. \& Keith, J.E. (2000) Estimating the recreation demand and economic value of mountain biking in Moab, Utah: an application of count data models, Journal of Environmental Planning and Management, 43, pp. 461-469.

Dardis, R., Soberon-Ferrer, M. \& Patro, D. (1994) Analysis of leisure expenditures in the United States, Journal of Leisure Research, 26, pp. 309-321.

Englin, J. \& Shonkwiler, J.S. (1995) Estimating social welfare using count data models: an application to long-run recreation demand under conditions of endogenous stratification and truncation, Review of Economics and Statistics, 77, pp. 104-112.

Grogger, J.T. \& Carson, R.T. (1991) Models for truncated counts, Journal of Applied Econometrics, 6, pp. 225-238.

Haab, T.C. \& McConnell, K.E. (1996) Count data models and the problem of zeros in recreation demand analysis, American Journal of Agricultural Economics, 78, pp. 89-102.

Jefferes, L.W. \& Dobos, J. (1993) Perceptions of leisure opportunities ad the quality of life in a metropolitan area, Journal of Leisure Research, 25, pp. 203-217.

Johnson, N.L., Kotz, S. \& Kemp, A.W. (1972) Univariate Discrete Distributions (New York, John Wiley and Sons).

Kay, T. \& Jackson, G. (1991) Leisure despite constraint: the impact of leisure constraints on leisure participation, Journal of Leisure Research, 23, pp. 301-313. 
Kuentzel, W.F. \& Heberlein, T.A. (1997) Social status, self-development, and the process of sailing specialization, Journal of Leisure Research, 29, pp. 300-319.

Lambert, D. (1992) Zero-inflated Poisson regression, with an application to defects in manufacturing, Technometrics, 34, pp. 1-14.

Marine Institute (1997) A National Survey of Water-based Leisure Activities (Dublin, Marine Institute).

Marine Institute (2000) Investment Programme 2000-2006 for the Water-based Tourism and Leisure Sector in Ireland (Dublin, Marine Institute).

NDP (1999) National Development Plan 2000-2006 (Dublin, Stationery Office).

Orthner, D.K. \& Mancini, J.A. (1990) Leisure impacts on family interaction and cohesion, Journal of Leisure Research, 22, pp. 125-137.

Shaw, S.M., Bonen, A. \& McCabe, J.F. (1991) Do more constraints mean less leisure? Examining the relationship between constraints and participation, Journal of Leisure Research, 23, pp. 286-300.

Shaw, W.D. \& Jakus, P. (1996) Travel cost models of the demand for rock climbing, Agricultural and Resource Economics Review, 25, pp. 133-142.

Shonkwiler, J.S. \& Shaw, W.D. (1996) Hurdle count-data models in recreation demand analysis, Journal of Agricultural and Resource Economics, 21, pp. 210-219. 
